\title{
Menopausal hormone therapy and new-onset diabetes in the French Etude Epidemiologique de Femmes de la Mutuelle Générale de l'Education Nationale (E3N) cohort
}

\author{
B. de Lauzon-Guillain - A. Fournier • A. Fabre • \\ N. Simon • S. Mesrine • M-C. Boutron-Ruault • \\ B. Balkau • F. Clavel-Chapelon
}

Received: 8 April 2009 /Accepted: 22 June 2009 /Published online: 23 July 2009

(C) Springer-Verlag 2009

\begin{abstract}
Aims/hypothesis Two US randomised trials found a lower incidence of type 2 diabetes in women treated by menopausal hormone therapy (MHT) with oral conjugated equine oestrogen combined with medroxyprogesterone acetate. The purpose of this study was to evaluate the influence of various MHTs, according to their formulation and route of administration, on new-onset diabetes in a cohort of postmenopausal French women.

Methods The association between MHT use and new-onset diabetes was investigated by Cox regression analysis in 63,624 postmenopausal women in the prospective French cohort of the Etude Epidemiologique de Femmes de la Mutuelle Générale de l'Education Nationale (E3N). Cases of diabetes were identified through self-reporting or drugreimbursement record linkage, and further validated.

Results 1,220 new-onset diabetes cases were validated. We observed a lower risk of new-onset diabetes among women who had ever used MHT (HR 0.82 [95\% CI 0.72-0.93]), compared with those who had never used MHT. Adjustment for BMI during follow-up (rather than according to baseline BMI) did not substantially modify this association.
\end{abstract}

B. de Lauzon-Guillain $\cdot$ A. Fournier $\cdot$ A. Fabre $\cdot$ N. Simon

S. Mesrine $\cdot$ M.-C. Boutron-Ruault $\cdot$ F. Clavel-Chapelon $(\square)$

INSERM, ERI 20, EA 4045, Institut Gustave-Roussy,

39 rue Camille Desmoulins,

94805 Villejuif cedex, France

e-mail: clavel@igr.fr

B. Balkau

INSERM, U780,

Villejuif, France

B. Balkau

Université Paris-Sud,

Orsay, France
An oral route of oestrogen administration was associated with a greater decrease in diabetes risk than a cutaneous route (HR 0.68 [95\% CI $0.55-0.85]$ vs 0.87 [95\% CI $0.75-1.00], p$ for homogeneity $=0.028$ ). We were not able to show significant differences between the progestagens used in combined MHT.

Conclusions/interpretation Use of MHT appeared to be associated with a lower risk of new-onset diabetes. This relationship was not mediated by changes in BMI. Further studies are needed to confirm the stronger effect of oral administration of oestrogen compared with cutaneous administration.

Keywords Adult diabetes $\cdot$ Cohort study $\cdot$ Menopausal hormone therapy $\cdot$ Postmenopause

\begin{tabular}{|c|c|}
\hline \multicolumn{2}{|c|}{ Abbreviations } \\
\hline E3N & Etude Epidemiologique de Femmes de la \\
\hline & $\begin{array}{l}\text { Mutuelle Générale de l'Education Nationale } \\
\text { (prospective cohort) }\end{array}$ \\
\hline HERS & Heart and Estrogen/Progestin Replacement Study \\
\hline MGEN & $\begin{array}{l}\text { Mutuelle Générale de l'Education Nationale } \\
\text { (national health insurance plan for teachers and } \\
\text { co-workers) }\end{array}$ \\
\hline MHT & Menopausal hormone therapy \\
\hline MPA & Medroxyprogesterone acetate \\
\hline WHI & Women's Health Initiative (trial) \\
\hline
\end{tabular}

Introduction

Diabetes mellitus is one of the most common chronic diseases in the industrialised world [1]. In France, the prevalence of treated diabetes was estimated to be $3.6 \%$ in 
2005 [2]. The World Health Organization predicts that the number of patients with diabetes worldwide will rise from 171 million in 2000 to more than 366 million in 2030 [3]. Diabetes prevalence is generally similar in men and women [3] and is higher in overweight and obese individuals [4-6].

Steroid hormones may influence diabetes onset. Animal studies have indeed suggested that ovarian hormone deficiency is associated with increased insulin resistance $[7,8]$. Impaired glucose tolerance and insulin resistance are known to increase with age [9], but it is still unclear if menopause per se modifies this increase [10]. Compared with premenopausal women, postmenopausal women have similar glucose and insulin levels and a relatively minor deterioration in glucose tolerance, but they have an increased insulin resistance, produce less insulin and clear it more slowly [11]. Moreover, menopausal hormone therapy (MHT) has been shown to reverse the effects of the menopause on insulin secretion and clearance [11].

Two randomised trials, the Heart and Estrogen/Progestin Replacement Study (HERS) and the Women's Health Initiative (WHI) trial, examined the effects of $0.625 \mathrm{mg}$ conjugated equine oestrogen alone or combined with $2.5 \mathrm{mg}$ medroxyprogesterone acetate (MPA) on diabetes incidence [12-14]. These trials found a significant reduction in the incidence of diabetes of $20 \%$ to $30 \%$ in users of combined MHT $[12,13]$, and of $12 \%$ in users of oestrogen alone [14]. There was also a significant fall in insulin resistance during the first year of follow-up in women treated with combined MHT or oestrogens alone [13, 14]. Similarly, a recent meta-analysis examining components of the metabolic syndrome, which included 107 randomised controlled trials of at least 8 weeks' duration, showed that MHT reduced the risk of new-onset diabetes [15]. The results of observational studies are inconsistent [16-19].

Most trials have evaluated oral conjugated equine oestrogens given alone or associated with either MPA or 19-nortestosterone derivatives, but not with other combined oestrogen-progestagen therapies used in other parts of the world, nor with non-oral oestrogens. So it is still unclear whether some MHTs are more beneficial than others. In France, oestrogen - mostly oestradiol administered through the skin - is used alone or in combination with a variety of progestagens. The purpose of the present study was to evaluate the influence of MHTs, and their type and route of administration, on the risk of new-onset diabetes in a cohort of postmenopausal French women.

\section{Methods}

Participants The Etude Epidemiologique de Femmes de la Mutuelle Générale de l'Education Nationale (E3N), Mutuelle Générale de l'Education Nationale (MGEN) was initiated in France in 1990 to investigate factors associated with cancers in women [20]. The prospective cohort included 98,995 women living in France, aged 40-65 years in 1990, who were covered by the national health insurance plan for teachers and co-workers. All women signed an informed consent, in compliance with the rules of the French National Commission for Computed Data and Individual Freedom (Commission National Informatique et Libertés) from which approval was obtained. In 1990 and at follow-up (1992, 1993, 1995, 1997, 2000, 2002 and 2005), women completed self-administered questionnaires with questions on demographic and anthropometric characteristics, reproductive history, health status, parental diabetes and smoking status.

Definition and validation of an incident case of diabetes A first set of potential cases of diabetes included women who had self-reported at least one of the following in at least one of the eight questionnaires sent up until July 2005: diabetes; a diabetes diet; use of diabetic drugs; or hospitalisation for diabetes. A total of 4,289 potential self-reported cases were identified. Among them, 2,315 cases were validated because women were identified as having been reimbursed for a diabetic drug by the health insurance provider between 1 January 2004 (when the file became available) and 30 June 2007 (endpoint of the present study). Among the 1,974 women without evidence of reimbursement for diabetic drugs, those alive and with an accurate address $(n=1,735)$ were sent a questionnaire specifically designed to validate diabetes. From the 1,480 women who completed this questionnaire (response rate: 84\%), 342 cases were confirmed by meeting at least one of the following criteria: glucose concentration at diagnosis reported to comply with WHO recommendations (fasting glucose $\geq 7.0 \mathrm{mmol} / 1$ or random glucose $\geq 11.1 \mathrm{mmol} / 1$ ) [21]; reported to be taking diabetic drugs; and/or the last value of fasting glucose or $\mathrm{HbA}_{1 \mathrm{c}}$ reported to be $\geq 7.0 \mathrm{mmol} / 1$ and/or $\geq 7 \%$, respectively $[22,23]$. A total of 2,657 self-reported diabetes cases were validated in this way.

A second set of potential cases of diabetes was identified exclusively from the drug-reimbursement file $(n=1,216)$ without prior report of diabetes in any of the eight study questionnaires. We sent the diabetes-specific questionnaire to 1,139 of these women and 734 completed it. We considered: as non-cases, women who declared they were not diabetic and who had been reimbursed for diabetic drugs only once before 30 June $2007 \quad(n=233)$; as validated diabetic cases, women who confirmed diabetes in the diabetes-specific questionnaire $(n=458)$ and those who did not answer the diabetes-specific questionnaire but had diabetic drugs reimbursed at least twice $(n=381)$. Other potential cases were considered nonvalidated $(n=144)$. 
Taken together, a total of 3,496 diabetes cases diagnosed until 30 June 2007 were thus validated in the E3N cohort.

Although this procedure did not systematically allow differentiation between type 1 and type 2 diabetes mellitus, the age range of our population implies that incident cases considered in our analyses are mostly type 2 diabetes mellitus. Diabetes cases diagnosed before the start of the follow-up were excluded (see below).

Identification of MHT use Information on lifetime use of hormonal treatments was recorded in the 1992 questionnaire and included the start date and duration of each episode of hormone use, together with the corresponding brand name of the product used. To help women remember what brand they had taken, they were given a booklet with colour photographs of the hormonal treatments marketed in France. The information was updated in each of the subsequent questionnaires.

Population for analysis and follow-up The present analysis included only the women who responded to a dietary history questionnaire sent in 1993 (Fig. 1), with the data providing the baseline to allow adjustment for energy and alcohol intake. After two reminders to non-respondents, 77,613 dietary questionnaires were returned $(81.1 \%$ response rate). Of these questionnaires, 2,104 were excluded because of miscoding and 985 because respondents did not give their consent to a follow-up by the health insurer (MGEN) if they dropped out. We also excluded 1,490 women who returned questionnaires reporting an unrealistic intake of total energy, as defined by the 1st and 99th percentile of the ratio of energy intake to basal metabolic rate computed on the basis of age, height and weight at the time of the dietary survey [24], and 368 women who did not complete the part of this questionnaire that enquired about their health status.

In the present analysis, only postmenopausal women were included. Women were considered postmenopausal if they had had 12 consecutive months without menstrual periods (unless this was because of hysterectomy), had undergone bilateral oophorectomy, had ever used MHT or if they self-reported that they were postmenopausal. Age at menopause was defined as: age at last menstrual period (if the last menstrual period occurred before MHT use and cessation was not consequent to hysterectomy); age at bilateral oophorectomy; in decreasing order of priority, self-reported age at menopause, age at start of MHT, age at start of menopausal symptoms; or, if no information was available, 47 years if menopause was artificial, and 51 years otherwise, ages that corresponded with the median values for artificial and natural menopause in the cohort, respectively.

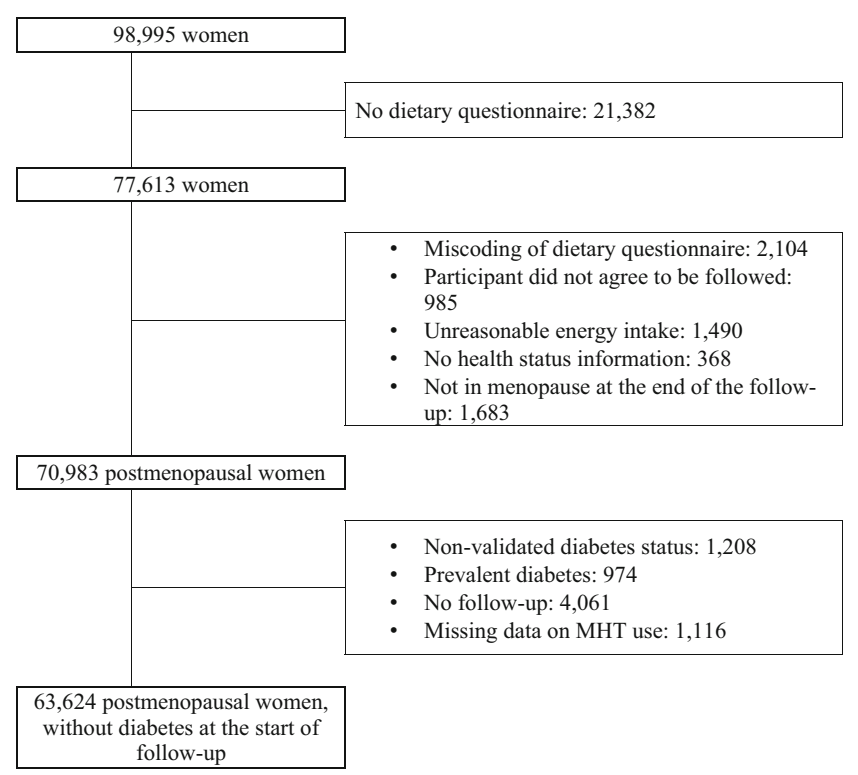

Fig. 1 Exclusion criteria for the analysis of the influence of MHT on diabetes risk in the E3N, France

Among the women with validated dietary questionnaires $(n=72,666), 70,983$ women were postmenopausal at the time of the 8th questionnaire; we excluded those with nonvalidated diabetes or no date of diagnosis $(n=1,208)$, those who had been diagnosed with diabetes before the dietary questionnaire or first report of menopause $(n=974)$, those with no follow-up $(n=4,061)$, and those who did not answer the questionnaire (sent in 1992) about lifetime use of MHT while being postmenopausal at that date $(n=1,116)$, leaving 63,624 women for analysis.

Follow-up started either at the date of return of the dietary questionnaire for the women who were already postmenopausal or at the date of the first report of menopause. Women were included in the analyses until the date of diagnosis of diabetes, the date of the last completed questionnaire if the 2005 questionnaire was not completed or 30 June 2007, whichever occurred first.

Statistical analysis We used Cox proportional hazards regression models stratified by 5 year interval birth cohorts, with age as the timescale, to estimate the hazards ratios for diabetes and 95\% confidence intervals [25]. We controlled for potential confounders by adjusting the model for educational level, physical activity in 1993 (energy expenditure calculated by multiplying the duration of daily physical activities by the estimated metabolic energy spent [26]), age at menarche, parity, breastfeeding, type of menopause, age of menopause, family history of diabetes, cholesterol level, hypertension, alcohol intake, energy intake, smoking and BMI. Data on smoking and hypertension were entered in the models as time-dependent variables. Cut-offs for covariables are indicated in the 
footnotes of Table 2 . We replaced missing values by the modal value (all were categorical variables) when occurring in fewer than $5 \%$ of women, or else by a 'missing' category.

As being overweight is a major risk factor for diabetes [27] and MHT use is associated with a lower increase in fat mass $[15,28-31]$, BMI may be an intermediate factor in the relationship between MHT exposure and diabetes risk. We therefore decided to present two different models. The first was adjusted for potential confounders and baseline BMI; the second was adjusted for potential confounders and BMI during follow-up as a time-dependant variable.

Regarding MHT exposure status, the information reported in questionnaires ' $n$ ' and earlier was used to prospectively categorise participants for the period between completion of questionnaire ' $n$ ' and completion of questionnaire ' $n+1$ ' (or end of follow-up). For women who did not answer questionnaire ' $n$ ', MHT exposure status was classified as missing for the period between the date at which questionnaire ' $n$ ' was sent to the participants and the date of completion of the subsequent questionnaire (or end of follow-up). In estimating the HRs associated with different types of MHT, estimates were computed for the MHT used for the longest duration in the case of treatment change during follow-up.

All tests of statistical significance were two-sided, and the significance was set at the 0.05 level. The $p$ values for assessing possible heterogeneity in effect estimates were computed from likelihood ratio tests. We performed all analyses using SAS software, version 9.1 (SAS Institute, Cary, NC, USA).

\section{Results}

A total of 1,220 new-onset diabetes cases were validated during 663,087 person-years of follow-up (mean duration: 10.4 years; SD 3.6). Table 1 shows selected characteristics of women according to their use of MHT. Compared with women who had never used MHT, women who had used MHT: appeared to have had a higher level of education; were less likely to have a family history of diabetes; were less often overweight; were more often parous; had, on average, an earlier menopause; and had a higher average cholesterol level. Women who had used MHT also had a higher yearly increase in BMI during follow-up than those who had never used MHT (0.07士 $0.27 \mathrm{vs} 0.06 \pm 0.35 \mathrm{~kg} \mathrm{~m}^{-2}$ year $\left.^{-1}\right)$ and this difference was significant even after adjustment for age and BMI at the start of follow-up $(p<0.001)$. Differences in women's characteristics at the start of follow-up were also found between those using oral and transdermal routes of oestrogen administration-pointing towards a better cardio-metabolic profile of oral oestrogen users-and between those using oestrogen only and oestrogen plus progestagen combinations.

Overall, the incidence of diabetes during follow-up was lower among MHT users than among those who had never used MHT (multivariate adjusted HR 0.82 [0.72-0.93]) (Table 2). Adjustment for BMI during follow-up rather than baseline BMI slightly enhanced the association (HR 0.75 [0.66-0.85]). Diabetes risk appeared not to be significantly related to the duration of MHT use. After 1 year of discontinuation of MHT, the protective effect was no longer significant when the model was adjusted for BMI during follow-up.

The decrease in risk of new-onset diabetes appeared significantly stronger for oestrogen administered orally (whether used alone or in association with a progestagen) rather than through the skin, even after adjustment for BMI during follow-up (HR 0.61 [0.50-0.76] vs 0.78 [0.67-0.90], $p=0.031$ ) (Table 2).

As some progestagens were combined only with oral or cutaneous oestrogen, we could not exclude the possibility that differences in HRs of new-onset diabetes reflected differences between progestagens. Thus, analyses were also performed according to route of oestrogen administration and type of progestagen (Table 3). For progestagens combined with either oral or cutaneous oestrogen, we were not able to show significant differences in HRs according to oestrogen route of administration. Similarly, for any given route of oestrogen administration, we observed no significant differences in HRs among progestagens. However, only cutaneous oestrogen combined with progesterone (it is rarely combined with oral oestrogens), as well as oral oestrogen combined with cyproterone acetate or norethisterone acetate (it is rarely combined with cutaneous oestrogens) were associated with a statistically significant lower risk of diabetes than in the group who had never used MHT, even after controlling for BMI during follow-up (HR 0.67 [0.54-0.84], $0.44[0.23-0.85]$ and 0.44 [0.26-0.75], respectively).

Compared with no use of MHT, use of weak oestrogens (orally or vaginally administered promestriene or oestriol) was associated with a lower risk of incident diabetes when analyses were adjusted for BMI during follow-up (HR 0.70 [0.50-0.97]) but not when adjusted for baseline BMI (HR 0.74 [0.53-1.04]) (data not tabulated, 43 cases/2,374 women using weak oestrogens).

All results were confirmed following sensitivity analyses including non-validated diabetes cases and estimates were consistent with the main results presented (data not shown). 
Table 1 Selected characteristics (mean [SD]/n [\%]) of participants at the start of follow-up according to, as recorded at the end of the follow-up: (1) use of menopausal hormone therapy (MHT) use; (2) route of oestrogen administration; (3) association of progestagen, in the E3N, France (1993-2007, $N=63,624)$

\begin{tabular}{|c|c|c|c|c|c|c|c|c|}
\hline \multirow[t]{2}{*}{ Characteristic } & \multicolumn{2}{|l|}{ MHT use } & \multicolumn{3}{|c|}{ Route of oestrogen administration } & \multicolumn{3}{|c|}{ Type of MHT } \\
\hline & Non-user & User & Oral & $\begin{array}{l}\text { Transdermal/ } \\
\text { cutaneous }\end{array}$ & $\begin{array}{l}\text { Other/ } \\
\text { unknown }\end{array}$ & $\begin{array}{l}\text { Oestrogen } \\
\text { alone }\end{array}$ & $\begin{array}{l}\text { Oestrogen }+ \\
\text { progestagen }\end{array}$ & $\begin{array}{l}\text { Other/ } \\
\text { unknown }\end{array}$ \\
\hline Number of participants & 18,230 & 45,394 & 11,263 & 25,740 & 8,391 & 4,656 & 30,905 & 9,833 \\
\hline $\begin{array}{l}\text { Age at start of } \\
\text { follow-up, years }\end{array}$ & $57.1(5.5)$ & $54.8(4.7)^{\mathrm{a}}$ & $53.6(4.1)$ & $54.5(4.3)^{\mathrm{b}}$ & $57.1(5.4)$ & $54.8(5.1)$ & $54(4.1)^{\mathrm{c}}$ & $56.9(5.4)$ \\
\hline $\begin{array}{l}\text { Age at menopause, } \\
\text { years }\end{array}$ & $50.7(3.9)$ & $50.1(3.7)^{\mathrm{a}}$ & $50.2(3.6)$ & $50.2(3.5)$ & $49.7(4.4)$ & $49.4(4.4)$ & $50.3(3.3)^{\mathrm{c}}$ & $49.8(4.4)$ \\
\hline University degree & $\begin{array}{l}6,000 \\
(32.9 \%)\end{array}$ & $\begin{array}{l}16,465 \\
(36.3 \%)^{\mathrm{a}}\end{array}$ & $\begin{array}{l}4,427 \\
\quad(39.3 \%)\end{array}$ & $\begin{array}{l}9,182 \\
(35.7 \%)^{\mathrm{b}}\end{array}$ & $\begin{array}{l}2,856 \\
(34.0 \%)\end{array}$ & $\begin{array}{l}1,440 \\
(30.9 \%)\end{array}$ & $\begin{array}{l}11,632 \\
(37.6 \%)^{\mathrm{c}}\end{array}$ & $\begin{array}{l}3,393 \\
\quad(34.5 \%)\end{array}$ \\
\hline $\begin{array}{l}\text { Age at menarche } \\
\geq 13 \text { years }\end{array}$ & $\begin{array}{l}9,833 \\
\quad(53.9 \%)\end{array}$ & $\begin{array}{l}24,478 \\
(53.9 \%)\end{array}$ & $\begin{array}{l}6,075 \\
\quad(53.9 \%)\end{array}$ & $\begin{array}{l}13,816 \\
(53.7 \%)\end{array}$ & $\begin{array}{l}4,587 \\
(54.7 \%)\end{array}$ & $\begin{array}{l}2,380 \\
\quad(51.1 \%)\end{array}$ & $\begin{array}{l}16,720 \\
(54.1 \%)^{\mathrm{c}}\end{array}$ & $\begin{array}{l}5,378 \\
(54.7 \%)\end{array}$ \\
\hline Parous & $\begin{array}{l}2,600 \\
(14.3 \%)\end{array}$ & $\begin{array}{l}4,912 \\
(10.8 \%)^{\mathrm{a}}\end{array}$ & $\begin{array}{l}1,121 \\
(10 \%)\end{array}$ & $\begin{array}{l}2,743 \\
(10.7 \%)^{\mathrm{b}}\end{array}$ & $\begin{array}{l}1,048 \\
(12.5 \%)\end{array}$ & $\begin{array}{l}543 \\
(11.7 \%)\end{array}$ & $\begin{array}{l}3,161 \\
(10.2 \%)^{\mathrm{c}}\end{array}$ & $\begin{array}{l}1,208 \\
(12.3 \%)\end{array}$ \\
\hline Parent with diabetes & $\begin{array}{l}5,341 \\
(29.3 \%)\end{array}$ & $\begin{array}{l}10,597 \\
(23.3 \%)^{\mathrm{a}}\end{array}$ & $\begin{array}{l}2,537 \\
(22.5 \%)\end{array}$ & $\begin{array}{l}5,964 \\
(23.2 \%)\end{array}$ & $\begin{array}{l}2,096 \\
(25 \%)\end{array}$ & $\begin{array}{l}1,144 \\
(24.6 \%)\end{array}$ & $\begin{array}{l}7,073 \\
(22.9 \%)^{\mathrm{c}}\end{array}$ & $\begin{array}{l}2,380 \\
(24.2 \%)\end{array}$ \\
\hline Smoker & $\begin{array}{l}5,282 \\
(29 \%)\end{array}$ & $\begin{array}{c}14,536 \\
(32 \%)^{\mathrm{a}}\end{array}$ & $\begin{array}{l}3,778 \\
\quad(33.5 \%)\end{array}$ & $\begin{array}{l}8,120 \\
(31.5 \%)^{\mathrm{b}}\end{array}$ & $\begin{array}{l}2,638 \\
(31.4 \%)\end{array}$ & $\begin{array}{l}1,469 \\
(31.6 \%)\end{array}$ & $\begin{array}{l}9,964 \\
(32.2 \%)^{\mathrm{c}}\end{array}$ & $\begin{array}{l}3,103 \\
\quad(31.6 \%)\end{array}$ \\
\hline BMI $\left(\mathrm{kg} / \mathrm{m}^{2}\right)$ & $23.8(3.8)$ & $22.9(3.1)^{\mathrm{a}}$ & $22.7(3.0)$ & $23.0(3.1)^{\mathrm{b}}$ & $23.1(3.1)$ & $23.4(3.4)$ & $22.8(3.0)^{\mathrm{c}}$ & $23.1(3.1)$ \\
\hline $\begin{array}{l}\text { Breastfeeding } \\
>12 \text { months }\end{array}$ & $\begin{array}{l}1,254 \\
(6.9 \%)\end{array}$ & $\begin{array}{l}2,026 \\
(4.5 \%)^{\mathrm{a}}\end{array}$ & $\begin{array}{l}432 \\
(3.8 \%)\end{array}$ & $\begin{array}{l}1,113 \\
(4.3 \%)^{b}\end{array}$ & $\begin{array}{l}481 \\
(5.7 \%)\end{array}$ & $\begin{array}{l}213 \\
(4.6 \%)\end{array}$ & $\begin{array}{l}1,268 \\
(4.1 \%)\end{array}$ & $\begin{array}{l}545 \\
(5.5 \%)\end{array}$ \\
\hline $\begin{array}{l}\text { Cholesterol }^{\mathrm{d}} \\
>5.1 \mathrm{mmol} / 1\end{array}$ & $\begin{array}{l}7,604 \\
(41.7 \%)\end{array}$ & $\begin{array}{l}20,734 \\
(45.7 \%)^{\mathrm{a}}\end{array}$ & $\begin{array}{l}4,382 \\
(38.9 \%)\end{array}$ & $\begin{array}{l}11,997 \\
(46.6 \%)^{\mathrm{b}}\end{array}$ & $\begin{array}{l}4,355 \\
\quad(51.9 \%)\end{array}$ & $\begin{array}{l}2,216 \\
(47.6 \%)\end{array}$ & $\begin{array}{l}13,518 \\
(43.7 \%)^{\mathrm{c}}\end{array}$ & $\begin{array}{l}5,000 \\
\quad(50.8 \%)\end{array}$ \\
\hline Hypertension & $\begin{array}{l}2,006 \\
(11.0 \%)\end{array}$ & $\begin{array}{l}4,031 \\
(8.9 \%)^{\mathrm{a}}\end{array}$ & $\begin{array}{l}703 \\
(6.2 \%)\end{array}$ & $\begin{array}{l}2,398 \\
(9.3 \%)^{b}\end{array}$ & $\begin{array}{l}930 \\
(11.1 \%)\end{array}$ & $\begin{array}{l}493 \\
(10.6 \%)\end{array}$ & $\begin{array}{l}2,484 \\
(8.0 \%)^{\mathrm{c}}\end{array}$ & $\begin{array}{l}1,054 \\
(10.7 \%)\end{array}$ \\
\hline $\begin{array}{l}\text { Physical activity }{ }^{\mathrm{e}} \text { (MET- } \\
\text { h/week) }\end{array}$ & $41.1(28.9)$ & $39.8(27.3)^{\mathrm{a}}$ & $39(26.8)$ & $39.8(27.3)^{\mathrm{b}}$ & $41(28.1)$ & $\begin{array}{l}40.5 \\
(27.9)\end{array}$ & $39.3(27.0)^{\mathrm{c}}$ & $\begin{array}{l}40.9 \\
(27.8)\end{array}$ \\
\hline Alcohol intake (g/day) & $10.5(14.1)$ & $11.5(14.1)^{\mathrm{a}}$ & $11.9(14.5)$ & $11.4(13.9)^{\mathrm{b}}$ & $11.2(14)$ & $\begin{array}{l}10.9 \\
(13.5)\end{array}$ & $11.6(14.2)^{\mathrm{c}}$ & $11.3(14.1)$ \\
\hline Energy intake (kJ/day) & $\begin{array}{l}8,931 \\
(2,423)\end{array}$ & $\begin{array}{l}9,051 \\
\quad(2,362)^{\mathrm{a}}\end{array}$ & $\begin{array}{l}9,077 \\
(2,342)\end{array}$ & $\begin{array}{l}9,069 \\
(2,362)\end{array}$ & $\begin{array}{l}8,958 \\
(2,386)\end{array}$ & $\begin{array}{l}9,065 \\
(2,364)\end{array}$ & $\begin{array}{l}9,071 \\
(2,359)\end{array}$ & $\begin{array}{l}8,981 \\
(2,369)\end{array}$ \\
\hline
\end{tabular}

${ }^{a}$ Significantly different from non-users of MHT, $p<0.05$

${ }^{\mathrm{b}}$ Significantly different from oral route of oestrogen administration, $p<0.05$

${ }^{\mathrm{c}}$ Significantly different from oestrogen only, $p<0.05$

${ }^{\mathrm{d}}$ A total of 8,863 women had missing data for this variable

${ }^{\mathrm{e}}$ A total of 26,536 women had missing data for this variable

MET-h/week, Metabolic equivalent cost-h/week

\section{Discussion}

In this prospective cohort, we observed a lower risk of newonset diabetes among women who had ever used MHT compared with those who had never used MHT. Adjustment for BMI during follow-up rather than baseline BMI did not substantially modify the association. An oral route of oestrogen administration was associated with a stronger decrease in diabetes risk than cutaneous administration. When further taking into account the type of progestagen in the combined MHT preparation, only cutaneous oestrogen combined with progesterone, or oral estrogen combined with cyproterone acetate or norethisterone acetate were significantly associated with a lower risk of diabetes, although there was no statistically significant heterogeneity between progestagens with regard to diabetes risk.

The process underlying the change in glucose and insulin levels with exposure to oestrogen is not fully understood, but several mechanisms have been hypothesised. Oestrogen may have a direct effect on the pancreatic secretion of insulin, as oestrogen receptors are present in pancreatic beta cells [32] and oestrogen increases the release of insulin in beta cell models [33]. Previous studies have also found that oestrogen may reduce peripheral vascular reactivity $[34,35]$. A decreased peripheral blood flow may limit insulin delivery and promote insulin resistance. Results of the WHI trial suggested that a decrease in insulin resistance, induced by the MHT, may 
Table 2 Hazard ratios $(95 \%$ CI) for new-onset diabetes according to duration of MHT use, recency of use, and route of oestrogen administration compared with non-use of MHT in the E3N, France $(1993-2007, N=63,624)$

\begin{tabular}{|c|c|c|c|}
\hline Group and variable & Case/total & $\begin{array}{l}\text { Model } 1^{\mathrm{a}} \\
\operatorname{HR}(95 \% \mathrm{CI})\end{array}$ & $\begin{array}{l}\text { Model } 2^{\mathrm{b}} \\
\text { HR }(95 \% \mathrm{CI})\end{array}$ \\
\hline MHT non-users & $518 / 18,230$ & 1 (reference) & 1 (reference) \\
\hline MHT users & $702 / 45,394$ & $0.82(0.72-0.93)$ & $0.75(0.66-0.85)$ \\
\hline \multicolumn{4}{|l|}{ Duration of MHT use (users) } \\
\hline $0-2$ years & $144 / 7,300$ & $0.79(0.64-0.96)$ & $0.75(0.61-0.91)$ \\
\hline $2-5$ years & $202 / 11,868$ & $0.89(0.74-1.06)$ & $0.84(0.70-1.00)$ \\
\hline$>5$ years & $294 / 23,460$ & $0.78(0.66-0.91)$ & $0.70(0.59-0.82)$ \\
\hline Unknown duration & $62 / 2,766$ & $0.92(0.70-1.21)$ & $0.75(0.57-1.00)$ \\
\hline$p$ value for homogeneity in duration of use & & 0.41 & 0.32 \\
\hline \multicolumn{4}{|l|}{ Use of MHT (users) } \\
\hline Current use & $422 / 7657$ & $0.83(0.71-0.96)$ & $0.78(0.68-0.89)$ \\
\hline Past use ( $>1$ year before) & $244 / 35,384$ & $0.78(0.66-0.93)$ & $0.90(0.76-1.07)$ \\
\hline Unknown recency & $36 / 2,353$ & $1.01(0.72-1.43)$ & $0.99(0.70-1.39)$ \\
\hline$p$ value for homogeneity in recency & & 0.55 & 0.09 \\
\hline \multicolumn{4}{|l|}{ Route of oestrogen administration ${ }^{c}$} \\
\hline Oral & $125 / 11,263$ & $0.68(0.55-0.85)$ & $0.61(0.50-0.76)$ \\
\hline Cutaneous & $425 / 25,740$ & $0.87(0.75-1.00)$ & $0.78(0.67-0.90)$ \\
\hline Other route ${ }^{\mathrm{d}}$ & $49 / 2,533$ & $0.81(0.59-1.11)$ & $0.76(0.56-1.04)$ \\
\hline Unknown route & $103 / 5,858$ & $0.84(0.67-1.05)$ & $0.73(0.59-0.92)$ \\
\hline$p$ value for homogeneity in oral and cutaneous routes & & 0.028 & 0.031 \\
\hline
\end{tabular}

${ }^{a}$ Model 1, adjusted for: age (timescale); age at menarche ( $<13$ years, $\geq 13$ years); parity (nulliparous/parous); breastfeeding (no, $<12$ months, $\geq 12$ months, unknown); age at menopause; type of menopause (artificial/natural/unknown); family history of diabetes (none, only one parent, both parents); physical activity in $1993(<19.8,19.8-33.4,33.4-53.2, \geq 53.2$ MET-h/week); alcohol intake (continuous); total energy intake exclusive of alcohol (continuous); education level $(\leq 9,10-11,12-14,15-16, \geq 17$ years); baseline cholesterol level ( $\leq 5.1,>5.1 \mathrm{mmol} / \mathrm{l})$; hypertension (yes/no, time-dependent variable); smoking (never/former/current smoker, time-dependent variable); and baseline BMI $(<22,22-25,25-27,27-30, \geq 30$ $\left.\mathrm{kg} / \mathrm{m}^{2}\right)$. Further stratified by year of birth (1925-1930, 1930-1935, 1935-1940, 1940-1945, 1945-1950)

${ }^{\mathrm{b}}$ Model 2, as model 1 with adjustment for: BMI $\left(<22,22-25,25-27,27-30, \geq 30 \mathrm{~kg} / \mathrm{m}^{2}\right)$ as a time-dependent variable

${ }^{\mathrm{c}}$ Corresponding to the MHT used for the greatest length of time

${ }^{\mathrm{d}}$ Vaginal, intramuscular or nasal

have been responsible for the lower incidence of diabetes observed in the women who received the active treatment $[13,14]$; these results were confirmed in a meta-analysis [15]. As in a recent study [36], the relationship was no longer significant after discontinuation of MHT use, when the model was adjusted for BMI during follow-up.

In the meta-analysis, MHT use was found to be associated with an increase in lean body mass and a decrease in abdominal fat [15], which could partially explain a reduced risk of diabetes in MHT users. Unfortunately, we were not able to assess potential MHT-induced changes in abdominal fat or lean mass as waist circumference was measured only once during the follow-up. In our study, associations between MHT use and new-onset diabetes tended to be stronger when adjusting for BMI during follow-up. This result could be explained by a greater increase in BMI during follow-up among MHT users. However, a recent systematic review concluded that there was no evidence for any difference in change in BMI with use of MHT from that normally experienced at the time of menopause [37]. In HERS [12], hormone therapy was associated with a significant decrease in waist circumference, but this change did not mediate the effect of MHT on diabetes risk. In the WHI trial, a greater nonsignificant increase in BMI was observed in treated women, probably because of an increase in lean body mass [28], but the effect of MHT on diabetes risk was also independent of changes in BMI and waist circumference [13].

Confirming our results of a difference between the oral and cutaneous route of oestrogen administration on the risk of new-onset diabetes, a recent meta-analysis found a larger protective effect on components of metabolic syndrome with oral MHT than with transdermal MHT [15], possibly because of a stronger effect of oral than transdermal oestradiol on peripheral vascular reactivity [34]. Few studies have examined associations with a given progestagen according to the route of administration of the associated oestrogen. When we compared the route of 
Table 3 Hazard ratios (95\% CI) for new-onset diabetes according to route of oestrogen administration and type of progestagen ${ }^{\text {a }}$ compared with MHT non-users in the E3N, France $(1993-2007, N=63,624)$

\begin{tabular}{|c|c|c|c|c|c|}
\hline \multirow[t]{2}{*}{ Variable } & \multicolumn{2}{|c|}{ Oral oestrogen } & \multicolumn{2}{|c|}{ Cutaneous oestrogen } & \multirow{2}{*}{$\begin{array}{l}p \text { value for } \\
\text { homogeneity in } \\
\text { routes of oestrogen } \\
\text { treatment }\end{array}$} \\
\hline & Cases/total ${ }^{\mathrm{b}}$ & HR $(95 \% \mathrm{CI})$ & Cases/total ${ }^{\mathrm{b}}$ & HR $(95 \% \mathrm{CI})$ & \\
\hline \multicolumn{6}{|l|}{ Model $1^{\mathrm{c}}$} \\
\hline Oestrogen only ${ }^{\mathrm{d}}$ & $16 / 796$ & $0.75(0.44-1.28)$ & $72 / 3,856$ & $0.87(0.67-1.13)$ & 0.62 \\
\hline \multicolumn{6}{|l|}{ Oestrogen combined with: } \\
\hline Progesterone & $4 / 674$ & $-{ }^{\mathrm{e}}$ & $112 / 7,725$ & $0.77(0.62-0.97)$ & - \\
\hline Dydrogesterone & $10 / 1,571$ & $0.62(0.33-1.16)$ & $86 / 4,455$ & $0.93(0.72-1.19)$ & 0.23 \\
\hline Medroxyprogesterone acetate & $22 / 1,453$ & $0.85(0.55-1.33)$ & $3 / 85$ & $-^{\mathrm{e}}$ & - \\
\hline Cyproterone acetate & $12 / 1,527$ & $0.50(0.26-0.97)$ & $2 / 159$ & $-{ }^{\mathrm{e}}$ & - \\
\hline Chlormadinone acetate & $5 / 424$ & $0.49(0.16-1.53)$ & $28 / 1,748$ & $0.95(0.63-1.42)$ & 0.28 \\
\hline Medrogestone & $2 / 272$ & $-{ }^{\mathrm{e}}$ & $24 / 1,167$ & $1.20(0.78-1.85)$ & - \\
\hline Nomegestrol acetate & $12 / 627$ & $1.07(0.57-2.02)$ & $56 / 3,272$ & $0.97(0.72-1.30)$ & 0.76 \\
\hline Promegestone & $13 / 805$ & $0.98(0.53-1.78)$ & $37 / 2,676$ & $0.81(0.57-1.15)$ & 0.58 \\
\hline Norethisterone acetate & $17 / 2,199$ & $0.48(0.28-0.81)$ & $0 / 25$ & $-{ }^{\mathrm{e}}$ & - \\
\hline $\begin{array}{l}p \text { value for homogeneity } \\
\text { in progestagens }\end{array}$ & & 0.35 & & 0.57 & \\
\hline \multicolumn{6}{|l|}{ Model $2^{\mathrm{f}}$} \\
\hline Oestrogen only & $16 / 796$ & $0.68(0.40-1.17)$ & $72 / 3,856$ & $0.80(0.61-1.04)$ & 0.59 \\
\hline \multicolumn{6}{|l|}{ Oestrogen combined with: } \\
\hline Progesterone & $4 / 674$ & $-{ }^{\mathrm{e}}$ & $112 / 7,725$ & $0.67(0.54-0.84)$ & - \\
\hline Dydrogesterone & $10 / 1,571$ & $0.58(0.31-1.09)$ & $86 / 4,455$ & $0.84(0.66-1.08)$ & 0.27 \\
\hline Medroxyprogesterone acetate & $22 / 1,453$ & $0.77(0.50-1.20)$ & $3 / 85$ & $-{ }^{\mathrm{e}}$ & - \\
\hline Cyproterone acetate & $12 / 1,527$ & $0.44(0.23-0.85)$ & $2 / 159$ & $-{ }^{\mathrm{e}}$ & - \\
\hline Chlormadinone acetate & $5 / 424$ & $0.45(0.14-1.40)$ & $28 / 1,748$ & $0.86(0.57-1.29)$ & 0.29 \\
\hline Medrogestone & $2 / 272$ & $-{ }^{\mathrm{e}}$ & $24 / 1,167$ & $1.01(0.66-1.56)$ & - \\
\hline Nomegestrol acetate & $12 / 627$ & $0.95(0.51-1.78)$ & $56 / 3,272$ & $0.88(0.66-1.18)$ & 0.83 \\
\hline Promegestone & $13 / 805$ & $0.89(0.49-1.63)$ & $37 / 2,676$ & $0.72(0.51-1.03)$ & 0.54 \\
\hline Norethisterone acetate & $17 / 2,199$ & $0.44(0.26-0.75)$ & $0 / 25$ & $-{ }^{\mathrm{e}}$ & - \\
\hline $\begin{array}{l}p \text { value for homogeneity } \\
\text { in progestagens }\end{array}$ & & 0.37 & & 0.47 & \\
\hline
\end{tabular}

${ }^{\text {a }}$ Corresponding to the MHT used for the greatest length of time

${ }^{\mathrm{b}}$ The number of cases and total of women do not add up to the totals as data are not tabulated for weak oestrogens (43 diabetes cases/2,376 total women), and other intramuscularly administered oestrogen or progestogen; androgen; nasally administered oestrogen; transdermally administered progestagen; or tibolone or unknown MHT (126 diabetes cases/7,457 total women)

${ }^{\mathrm{c}}$ Model 1: adjusted for the same covariates as model 1 in Table 2

${ }^{\mathrm{d}}$ Conjugated equine oestrogens were only marginally used by women in our cohort $(0.7 \%)$, so separate estimates for conjugated equine oestrogens and oestradiol compounds are not provided

${ }^{\mathrm{e}}$ Data are not presented as there are fewer than five cases in this MHT category

${ }^{\mathrm{f}}$ Model 2, as model 1 with adjustment for $\mathrm{BMI}\left(<22,22-25,25-27,27-30, \geq 30 \mathrm{~kg} / \mathrm{m}^{2}\right)$ as a time-dependent variable

oestrogen administration within a category of MHT (either oestrogen alone or according to the associated progestagen), we were not able to demonstrate any differences. However, we had too few cases to test the difference between routes of oestrogen administration within some progestagens (progesterone, MPA, cyproterone acetate and norethisterone acetate).

Though our study is the first to consider the effect of different types of MHT combination on diabetes risk, several authors have reported the impact of different types of hormone therapy on intermediate risk factors. In the WHI trial, conjugated equine oestrogen combined with MPA was found to improve insulin sensitivity [14]. Low-dose dydrogesterone associated with oestradiol may lead to a decrease in the concentration of circulating insulin [38]. Finally, oestrogen plus norethisterone acetate was found to have no effect on glucose and insulin metabolism [39], but seemed to improve insulin sensitiv- 
ity. The meta-analysis by Salpeter et al. [15] found no differences in insulin resistance between unopposed and combined treatments. In our study, we were not able to find any significant difference between the categories of MHT combinations on diabetes risk, but the number of cases of diabetes within each category of MHT combination for a given route of oestrogen administration may have been too low.

The major strength of our study is the range of MHTs evaluated and the fact that exposure was regularly updated during follow-up. This allowed us to limit the misclassification of MHT users and non-users, and users of a given MHT that can occur in prospective studies with a single baseline assessment of exposure. However, we acknowledge that we have limited power to examine the effects of the route of oestrogen administration within each category of progestagen and the effects of different progestagens within each route of oestrogen. Even if we cannot exclude the possibility that diabetes was not always reported, in particular for the women who were only given recommendations to improve their lifestyle, and that diabetes was not always diagnosed, we tried to limit the number of unreported diabetes cases by identifying diabetes cases not only by self-reporting but also by drug reimbursement. Other strengths of our study were the prospective design, the large sample and the long duration of follow-up. We acknowledge that the observational design of the study, in contrast to randomised clinical trials, cannot control for unknown baseline differences between MHT users and non-users, or between routes of oestrogen administration or types of MHT used. Nevertheless, we were able to adjust for the major risk factors for diabetes in our analyses, in particular BMI during all of the follow-up - a measure that, although selfreported, was found to be valid [40].

\section{Conclusion}

In conclusion, the use of MHT was associated with a reduction in the incidence of diabetes in postmenopausal women, even after careful control for BMI. Oral administration of oestrogen appeared to be associated with a lower risk of new-onset diabetes risk than cutaneous administration. However, because of the types of combinations prescribed, we were not able to assess the impact of the routes of administration for each type of progestagen.

Acknowledgements The authors are indebted to all participants for providing the data used in the $\mathrm{E} 3 \mathrm{~N}$ and to practitioners for providing pathology reports. They are grateful to R. Chaï, M. Fangon, L. Hoang, M. Niravong and J. Sahuquillo for their technical assistance, and to the E3N group. This work was carried out with the financial support of the: MGEN; European Community; French
League against Cancer (LNCC); Gustave Roussy Institute (IGR); French Institute of Health and Medical Research (INSERM); 3M Company; and several General Councils of France. The validation of potential diabetes cases was supported by the European Union (Integrated Project LSHM-CT-2006-037197 in the Framework Program 6 of the European Community), InterAct project. A. Fabre was a recipient of a grant from Canceropole-Region Ile-de-France. The funding sources had no involvement in the present work.

Duality of interest The authors declare that there is no duality of interest associated with this manuscript.

\section{References}

1. Adeghate E, Schattner P, Dunn E (2006) An update on the etiology and epidemiology of diabetes mellitus. Ann NY Acad Sci 1084:1-29

2. Kusnik-Joinville O, Weill A, Salanave B, Ricordeau P, Allemand $\mathrm{H}$ (2008) Prevalence and treatment of diabetes in France: trends between 2000 and 2005. Diabetes Metab 34:266-272

3. Wild S, Roglic G, Green A, Sicree R, King H (2004) Global prevalence of diabetes: estimates for the year 2000 and projections for 2030. Diabetes Care 27:1047-1053

4. Narayan KM, Boyle JP, Thompson TJ, Gregg EW, Williamson DF (2007) Effect of BMI on lifetime risk for diabetes in the U.S. Diabetes Care 30:1562-1566

5. Wannamethee SG, Shaper AG, Walker M (2005) Overweight and obesity and weight change in middle aged men: impact on cardiovascular disease and diabetes. J Epidemiol Community Health 59:134-139

6. Balkau B, Lange C, Fezeu L et al (2008) Predicting diabetes: clinical, biological, and genetic approaches: data from the Epidemiological Study on the Insulin Resistance Syndrome (DESIR). Diabetes Care 31:2056-2061

7. Bryzgalova G, Gao H, Ahren B et al (2006) Evidence that oestrogen receptor-alpha plays an important role in the regulation of glucose homeostasis in mice: insulin sensitivity in the liver. Diabetologia 49:588-597

8. Ordonez P, Moreno M, Alonso A, Fernandez R, Diaz F, Gonzalez C (2007) Insulin sensitivity in streptozotocin-induced diabetic rats treated with different doses of 17 beta-oestradiol or progesterone. Exp Physiol 92:241-249

9. Iozzo P, Beck-Nielsen H, Laakso M, Smith U, Yki-Jarvinen H, Ferrannini E (1999) Independent influence of age on basal insulin secretion in nondiabetic humans. European Group for the Study of Insulin Resistance. J Clin Endocrinol Metab 84:863-868

10. Bentley-Lewis R, Koruda K, Seely EW (2007) The metabolic syndrome in women. Nat Clin Pract Endocrinol Metabol 3:696-704

11. Godsland IF (2005) Oestrogens and insulin secretion. Diabetologia 48:2213-2220

12. Kanaya AM, Herrington D, Vittinghoff E et al (2003) Glycemic effects of postmenopausal hormone therapy: the Heart and Estrogen/progestin Replacement Study. A randomized, doubleblind, placebo-controlled trial. Ann Intern Med 138:1-9

13. Margolis KL, Bonds DE, Rodabough RJ et al (2004) Effect of oestrogen plus progestin on the incidence of diabetes in postmenopausal women: results from the Women's Health Initiative Hormone Trial. Diabetologia 47:1175-1187

14. Bonds DE, Lasser N, Qi L et al (2006) The effect of conjugated equine oestrogen on diabetes incidence: the Women's Health Initiative randomised trial. Diabetologia 49:459-468

15. Salpeter SR, Walsh JM, Ormiston TM, Greyber E, Buckley NS, Salpeter EE (2006) Meta-analysis: effect of hormone-replacement 
therapy on components of the metabolic syndrome in postmenopausal women. Diabetes Obes Metab 8:538-554

16. Rossi R, Origliani G, Modena MG (2004) Transdermal 17-betaestradiol and risk of developing type 2 diabetes in a population of healthy, nonobese postmenopausal women. Diabetes Care 27:645-649

17. Zhang Y, Howard BV, Cowan LD et al (2002) The effect of estrogen use on levels of glucose and insulin and the risk of type 2 diabetes in American Indian postmenopausal women: the strong heart study. Diabetes Care 25:500-504

18. Gabal LL, Goodman-Gruen D, Barrett-Connor E (1997) The effect of postmenopausal estrogen therapy on the risk of noninsulin-dependent diabetes mellitus. Am J Public Health 87:443445

19. Manson JE, Nathan DM, Krolewski AS, Stampfer MJ, Willett WC, Hennekens CH (1992) A prospective study of exercise and incidence of diabetes among US male physicians. JAMA 268:63-67

20. Fournier A, Fabre A, Mesrine S, Boutron-Ruault MC, Berrino F, Clavel-Chapelon F (2008) Use of different postmenopausal hormone therapies and risk of histology- and hormone receptordefined invasive breast cancer. J Clin Oncol 26:1260-1268

21. World Health Organization (2006) Definition and diagnosis of diabetes mellitus and intermediate hyperglycemia: report of a WHO/IDF consultation. WHO/IDF, Geneva, Switzerland. Available from www.who.int/diabetes/publications/Definition $\% 20$ and $\%$ 20diagnosis\%20of\%20diabetes_new.pdf, accessed 3 July 2009.

22. Kilpatrick ES (2008) Haemoglobin A1c in the diagnosis and monitoring of diabetes mellitus. J Clin Pathol 61:977-982

23. Saudek CD, Herman WH, Sacks DB, Bergenstal RM, Edelman D, Davidson MB (2008) A new look at screening and diagnosing diabetes mellitus. J Clin Endocrinol Metab 93:2447-2453

24. Schofield WN (1985) Predicting basal metabolic rate, new standards and review of previous work. Hum Nutr Clin Nutr 39 (Suppl 1):5-41

25. Thiebaut AC, Benichou J (2004) Choice of time-scale in Cox's model analysis of epidemiologic cohort data: a simulation study. Stat Med 23:3803-3820

26. Ainsworth BE, Haskell WL, Whitt MC et al (2000) Compendium of physical activities: an update of activity codes and MET intensities. Med Sci Sports Exerc 32:S498-504

27. Kopelman PG, Albon L (1997) Obesity, non-insulin-dependent diabetes mellitus and the metabolic syndrome. $\mathrm{Br}$ Med Bull 53:322-340

28. Chen Z, Bassford T, Green SB et al (2005) Postmenopausal hormone therapy and body composition - a substudy of the estrogen plus progestin trial of the Women's Health Initiative. Am J Clin Nutr 82:651-656
29. Chmouliovsky L, Habicht F, James RW, Lehmann T, Campana A, Golay A (1999) Beneficial effect of hormone replacement therapy on weight loss in obese menopausal women. Maturitas 32:147-153

30. Gambacciani M, Ciaponi M, Cappagli B, Genazzani AR (2001) Effects of low-dose continuous combined conjugated estrogens and medroxyprogesterone acetate on menopausal symptoms, body weight, bone density, and metabolism in postmenopausal women. Am J Obstet Gynecol 185:1180-1185

31. Thorneycroft IH, Lindsay R, Pickar JH (2007) Body composition during treatment with conjugated estrogens with and without medroxyprogesterone acetate: analysis of the women's Health, Osteoporosis, Progestin, Estrogen (HOPE) trial. Am J Obstet Gynecol 197(137):e131-137

32. Sutter-Dub MT (2002) Rapid non-genomic and genomic responses to progestogens, estrogens, and glucocorticoids in the endocrine pancreatic B cell, the adipocyte and other cell types. Steroids 67:77-93

33. Nadal A, Ropero AB, Fuentes E, Soria B, Ripoll C (2004) Estrogen and xenoestrogen actions on endocrine pancreas: from ion channel modulation to activation of nuclear function. Steroids 69:531-536

34. Vehkavaara S, Hakala-Ala-Pietila T, Virkamaki A et al (2000) Differential effects of oral and transdermal estrogen replacement therapy on endothelial function in postmenopausal women. Circulation 102:2687-2693

35. Zegura B, Keber I, Sebestjen M, Borko E (2003) Orally and transdermally replaced estradiol improves endothelial function equally in middle-aged women after surgical menopause. Am J Obstet Gynecol 188:1291-1296

36. Pentti K, Tuppurainen M, Honkanen R et al (2009) Hormone therapy protects from diabetes: the Kuopio Osteoporosis Risk Factor and Prevention Study. Eur J Endocrinol 160:979-983

37. Kongnyuy EJ, Norman RJ, Flight IH, Rees MC (1999) Oestrogen and progestogen hormone replacement therapy for perimenopausal and post-menopausal women: weight and body fat distribution. Cochrane Database Syst Rev, Issue 3. Art no.: CD001018. doi:10.1002/14651858.CD001018

38. Crook D, Godsland IF, Hull J, Stevenson JC (1997) Hormone replacement therapy with dydrogesterone and 17 beta-oestradiol: effects on serum lipoproteins and glucose tolerance during 24 month follow up. Br J Obstet Gynaecol 104:298-304

39. Luotola H, Pyorala T, Loikkanen M (1986) Effects of natural oestrogen/progestogen substitution therapy on carbohydrate and lipid metabolism in post-menopausal women. Maturitas 8:245253

40. Tehard B, van Liere MJ, Com Nougue C, Clavel-Chapelon F (2002) Anthropometric measurements and body silhouette of women: validity and perception. J Am Diet Assoc 102:1779-1784 